\title{
Effect of substrate availability and conspecific cues on communal oviposition in the apple murex snail Phyllonotus pomum
}

\author{
Cheryl A. Swanson ${ }^{1,2, *}$ \\ ${ }^{1}$ Department of Biological Science, Florida State University, Tallahassee, Florida 32306-1100, USA \\ ${ }^{2}$ Present address: Florida Department of Environmental Protection, 2600 Blair Stone Road MS 6515, Tallahassee, \\ Florida 32399-2400, USA
}

\begin{abstract}
Communal oviposition, the sharing of a single substrate by conspecific individuals for depositing clutches of egg capsules, is common among gastropod molluscs. In soft-bottom habitats, communal oviposition may occur because of a limitation of suitable hard substrate. Conspecific cues may be responsible for aggregating females. This study examined the oviposition behavior of the apple murex snail Phyllonotus pomum in seagrass beds in St. Joseph's Bay, Florida. Movement patterns obtained from a mark-recapture study conducted during the 5 mo prior to egg-laying season suggest that females are capable of moving, and often move, farther than the distance at which substrate might become limiting. In field surveys, 1 to greater than 14 possible suitable substrates were available within a $4 \mathrm{~m}$ radius of communal oviposition events, yet females still oviposited communally. In a caged field-substrate manipulation experiment, females contributed to a single communal egg-mass even when additional substrates were available within $0.25 \mathrm{~m}$. When given a choice between substrate without and with fresh egg capsules $(<8 \mathrm{~d}$ old $)$ in a caged field experiment, females deposited an equal number of clutches on each type of substrate. Communal oviposition in $P$. pomum was not mediated by substrate limitation, and previously laid conspecific egg capsules did not attract females or induce them to oviposit communally. Alternatively, there may be an adaptive advantage to communal oviposition in $P$. pomum. It is possible that the process of egg-laying from 1 individual attracts, aggregates and induces oviposition in neighboring females.
\end{abstract}

KEY WORDS: Substrate limitation · Oviposition · Egg-laying · Communal · Phyllonotus pomum · Muricidae $\cdot$ Gastropoda

\section{INTRODUCTION}

Availability and quality of hard substrate in soft bottom marine habitats can strongly influence reproduction and oviposition (Pechenik 1978, Brenchley 1981, D'Asaro 1986, DeMartini 1991, Kuhlmann 1997). Often the only hard substrate available in a soft bottom habitat is empty mollusc shells. These shell resources are dynamic and unpredictable in space and time, because shell availability depends on population dynamics of living molluscs and shells may be lost due to waves, tides, shifting sand or breakage from weakening shell strength (Kuhlmann 1997, 1998). Fasciolarid, thaid, and muricid gastropods require hard substrate on which to attach egg capsules (D'Asaro 2000). Communal oviposition, the sharing of hard substrate with conspecific individuals for depositing clutches of egg capsules, is a common behavior reported for these gastropods (D'Asaro 1970, 1986). Two alternative hypotheses for communal oviposition are that (1) a limitation of suitable hard substrate forces aggregation, or (2) females choose to oviposit communally. Observa- 


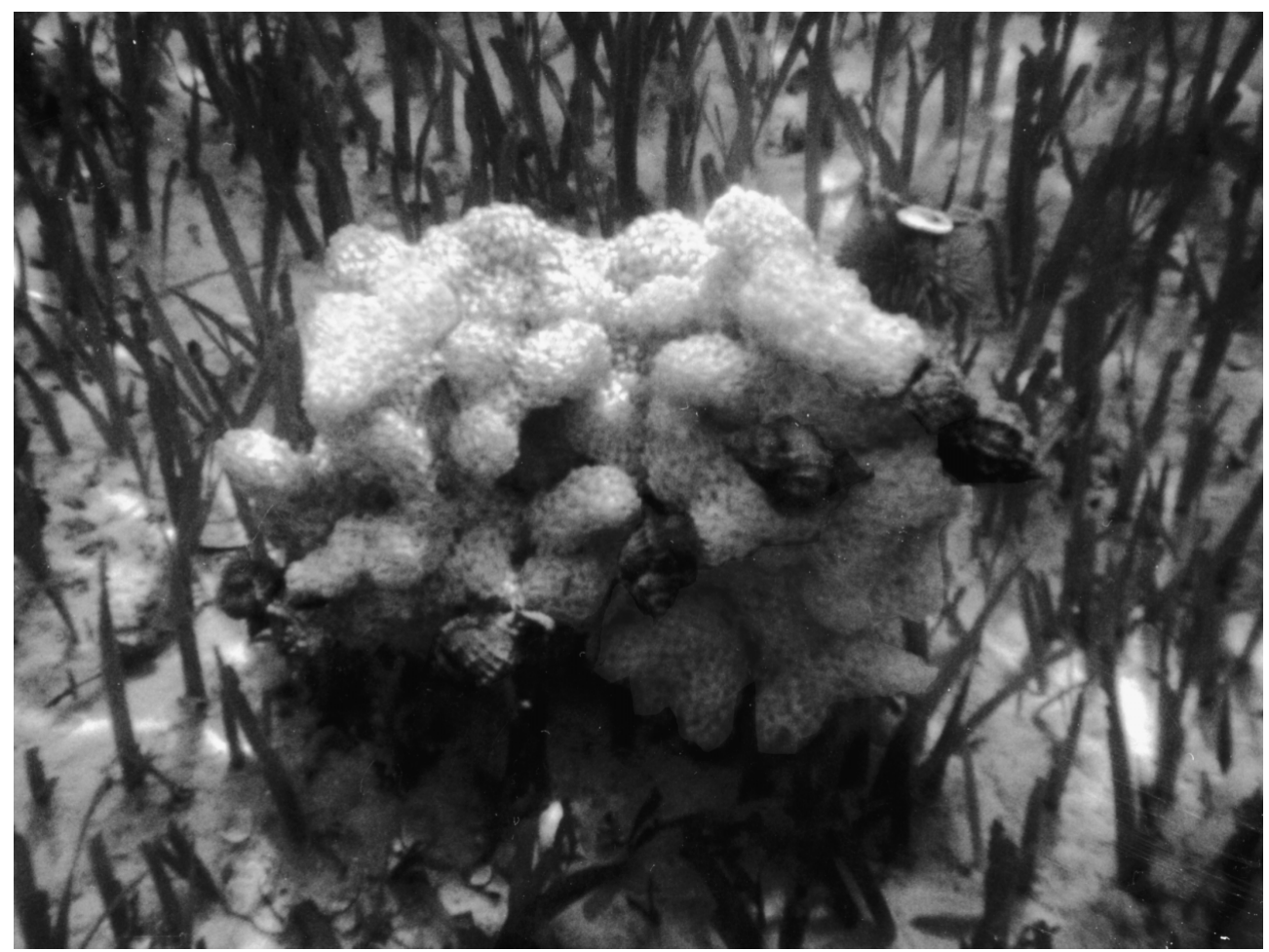

Fig. 1. Phyllonotus pomum. Female apple murex snails contributing clutches to a communal egg-mass $($ length $=31 \mathrm{~cm}$, height $=$ $27 \mathrm{~cm}$, volume $=2.3$ l) (Photo taken in St. Joseph's Bay, Florida, by C.A.S.)

tions of capsules attached to a conspecific's shell or capsules attached to other capsules, either horizontally or vertically, to extend beyond the initial surface suggest substrate limitation (D'Asaro 1993, 2000). The factors influencing site selection and oviposition decisions in communal egg-laying gastropods have not been clearly tested.

The apple murex snail Phyllonotus pomum is a muricid gastropod that oviposits communally (D'Asaro 1970, 1986). The species' range extends from South Carolina, USA, to the West Indies (Moore \& Sander 1977). This snail lives subtidally in sandy bottom habitats and deposits egg capsules on solid objects or clumps of the seagrass Thalassia (D'Asaro 1970). On the coast of Florida, females deposit clutches of egg capsules from late March to early May (Biscayne Bay: D'Asaro 1970; St. Joseph's Bay: pers. obs., this study). Multiple females deposit clutches simultaneously. Depending on when they arrive and begin egg-laying, they either attach their clutch to the substrate's surface or on top of another female's clutch that is being, or has just been, laid. The stacked individual clutches form a globular communal egg-mass that often overwhelms the substrate upon which it was begun (Fig. 1). Apple murex snails are reported to form the largest communal egg-masses in Northwest Florida, measuring up to
$50 \mathrm{~cm}$ diameter $\times 20 \mathrm{~cm}$ height, with the contributions of 2 to 100 individuals (D'Asaro 1970). In the extensive shallow (2 m depth) seagrass beds of St. Joseph's Bay, Florida in the northeastern Gulf of Mexico $\left(29^{\circ} 46.544^{\prime} \mathrm{N}, 85^{\circ} 24.120^{\prime} \mathrm{W}\right)$, where this research was conducted, up to 52 females were observed participating in a communal oviposition event which resulted in an egg-mass size measuring $40.5 \mathrm{~cm}$ length $\times 25.7 \mathrm{~cm}$ width $\times 18.3 \mathrm{~cm}$ height and reaching a volume of 31 (author's pers. obs.). For $P$. pomum females needing hard substrate on which to attach egg capsules, stacking clutches communally to such extreme egg-mass volumes may occur because of substrate limitation.

Conspecific attraction may be responsible for aggregating individuals at an oviposition site. Conspecific cues may signal high-quality sites or the presence of mates (Danchin \& Wagner 1997, Ramsay et al. 1999). The products of conspecifics, such as egg ribbons, can also attract and coordinate breeding behavior (Fan et al. 1997). D'Asaro (1970) proposed that a metabolite excreted by eggs and early embryos may induce a chemotactic response in prosobranch females. Because a communal egg-mass of Phyllonotus pomum often overwhelms the oviposition substrate, it seems likely that conspecific egg capsules might serve as a cue for aggregation. 
This study explores the 2 hypotheses, that: (1) Phyllonotus pomum oviposits communally because of substrate limitation, and (2) conspecific capsules are a cue for aggregation. Movement patterns of $P$. pomum were examined using a mark-recapture study to ascertain the scale over which substrates might be limiting. Field surveys were conducted to determine the type of hard substrate used for oviposition and the availability of substrate near communal oviposition events. To test whether females oviposit communally when additional substrate is available, a caged substrate manipulation experiment was conducted in the field. Because conspecific cues may influence oviposition behavior, a caged choice experiment was conducted in the field to test whether females use conspecific egg capsules as a cue for aggregation.

\section{MATERIALS AND METHODS}

Mark-recapture study. A mark-recapture study was conducted from September 1999 to March 2000 to monitor movements of Phyllonotus pomum in order to ascertain a spatial scale at which oviposition substrates may be limiting. A stake was placed in an area of seagrass containing $P$. pomum. Snails were collected from within an approximate $10 \mathrm{~m}$ radius around the stake and gender was determined by the presence or absence of a hook-shaped penis under the shell posterior to the right tentacle. Twenty-nine males and 37 females were measured from apex to tip of siphonal canal, and marked by gluing colored plastic labeling tape numbers to the shell. Each snail was released near its point of collection and allowed to acclimate for $1 \mathrm{wk}$ to reduce any effects of handling. The first sighting after the 1 wk acclimation was recorded as the start position. Every $2 \mathrm{wk}$, the area within a $20 \mathrm{~m}$ radius from the stake was surveyed. The distance and compass heading from a snail to the stake, and the snail's identification number and gender were recorded. Labeled snails found incidentally outside the observation area were also recorded. From these measurements, the positions of snails were mapped on a polar coordinate system using the north-south and east-west directions as axes, with the stake as the origin. The data were analyzed using SAS 8.01.

A daily rate of movement was calculated for each successive sighting by dividing the linear change in distance by the number of days since last sighting. Seasonal changes in the rate of movement were tested by averaging the rates for each sampling date and regressing these averages over time. To account for differences in the number of times an individual was recovered, the daily rates were averaged for each individual. Within gender, the correlation between the mean rate of movement and snail size was tested. Next, the mean rate of movement was calculated for each gender and compared using a $t$-test for equal variance. The gender mean rate of movement was used to estimate the average distance males and females traveled in $2 \mathrm{wk}$. These are conservative estimates because calculations are based on linear distance, while snails do not necessarily move in a straight line, and because snails that were never recovered might have moved beyond the area surveyed.

To examine whether or not apple murex move randomly within their environment, the distance between starting position and all subsequent positions was first calculated for each individual. An empirical distribution of the distance moved from start position was obtained for males and females by averaging all distances for each sampling date by gender. Next, a second distribution was generated by 100 iterations of a random walk model programmed in Microsoft Qbasic 1.0. The model chose a random direction from 0 to $360^{\circ}$ and used the estimated distance traveled in $2 \mathrm{wk}$ calculated from the rate of movement data to generate a new $x, y$ coordinate. The model then calculated the distance from the original origin $(0,0)$ to the new $x, y$ position at each of 11 time steps used to simulate sampling dates. Separate distributions were generated for males and females to reflect the slight gender difference in the average distance traveled, and because females are the gender of interest with regards to oviposition. Finally, the distribution of the empirical mean distances from start position was compared to the random walk distribution for each gender using the non-parametric Kolmogorov-Smirnov 2-sample test (Sokal \& Rohlf 1995).

Substrate use and availability. To determine which substrates apple murex use for depositing clutches, communal egg-masses at 2 sites in St. Joseph's Bay, Florida, were surveyed from April to May during the 2000 and 2001 egg-laying seasons. The type, length, and width of substrate was recorded for 41 completed egg-masses and 19 in-progress communal oviposition events in 2000, and for 21 completed egg-masses and 22 in-progress communal oviposition events in 2001. Differences in substrate use between the 2 egg-mass types, sites, and years were tested with $G$-tests for independence. The relationship between substrate area (length $\times$ width) and egg-mass volume was investigated using regression analysis.

In both years, the availability of additional oviposition substrate was surveyed near communal eggmasses in the process of being deposited. In 2000, a $4 \mathrm{~m} \times 4 \mathrm{~m}$ quadrat was centered on 19 communal eggmasses and the type and number of substrates were counted within 1 and 2 m of each egg-mass. In 2001, the survey area was expanded to circles of 2 and $4 \mathrm{~m}$ 
radii centered on 22 communal egg-masses. To examine whether substrate use reflected abundance, the substrate upon which communal egg-masses were being deposited was graphically compared to the proportion of substrates surrounding those communal oviposition events.

Substrate manipulation experiment. To test whether substrate limitation drives communal egg-laying behavior in Phyllonotus pomum, a caged substrate manipulation experiment was conducted in the field with 2 treatments: single and multiple shells. The null hypothesis tested was that females lay clutches randomly with respect to other females. In this scenario, communal oviposition is a consequence of substrate limitation. Alternatively, females might lay clutches non-randomly with respect to other females, in which case a communal egg-mass is a consequence of females choosing to lay with conspecifics.

In April 2001, twenty-four $2 \mathrm{~m}^{2}$ circular hardwire mesh cages (height $=30.5 \mathrm{~cm}$ ) were placed in the sand adjacent to a large seagrass bed where Phyllonotus pomum were found. The cage wall was buried approximately $4 \mathrm{~cm}$ deep to prevent snails from escaping under the cage and held in place using 22 gauge stainless steel wire stakes. The cages were cleared of all macroinvertebrates. Intact valves of dead pen shells (Atrina sp.) with less than $25 \%$ of a valve side covered with encrusting organisms and female apple murex were collected from the neighboring seagrass bed and sorted by size. For the single-shell treatment, one valve was placed in the center of 12 haphazardly selected cages. The multiple-shell treatment consisted of 15 valves haphazardly distributed in each of the remaining 12 cages. Each single-shell cage received the same size valve and each multiple shell cage received the same range of sizes. Female size ranged from 43.2 to $73.8 \mathrm{~mm}$. Six females of approximately the same size range were placed in each of the 24 cages. Lids were not used; instead, the tops of the cage walls were curled inward to discourage escape. It takes ca. 2 to $3 \mathrm{~d}$ for a female to deposit a clutch (Moore \& Sander 1977, author's pers. obs.). Cages were checked every $3 d$, with an occasional 4 to $5 \mathrm{~d}$ interval due to rough water. The tongue-shaped egg capsules of $P$. pomum are arranged in a circular manner and stacked like a house of cards (attached to one another at the bottom corners), forming a dome-shaped clutch that is slightly hollow in the middle. Because of this shape, it was possible to detect and document any new clutches that appeared during the $5 \mathrm{~d}$ interval, and also count the total number of clutches in a communal egg-mass. The number of females visible in the cage, number of exposed pen shells, number of females contributing a clutch to an egg-mass, number of clutches in an eggmass and number of egg-masses was recorded. During the experiment, an occasional sand dollar, sea star, urchin or crab was found in a cage and promptly removed. The volume of each egg-mass was recorded after females finished contributing clutches. The experiment was stopped in May after all oviposition ceased (35 d).

Because the expected values did not meet the assumptions for log-likelihood ratio goodness-of-fit tests, an index of dispersion test was used to test whether clutches were distributed randomly among shells (Sokal \& Rohlf 1995, Krebs 1999). For random distributions, variance is equal to the mean, and the index of dispersion is equal to 1 . Uniform distributions have an index of dispersion less than 1 , whereas aggregated distributions have an index of dispersion greater than 1. Indices were tested statistically using a chi-square distribution with $\mathrm{n}-1$ degrees of freedom (Krebs 1999, Zar 1999). $t$-tests for equal variance were used to compare the mean size of communal egg-masses between treatments and the mean size of communal and individual clutches within the multiple shell treatment.

Choice experiment. To test whether conspecific egg capsules are an attracting cue for females, a caged choice-experiment was conducted in the field, where females were given the choice of depositing a clutch on an empty pen shell or a pen shell with conspecific egg capsules. In April 2000, twelve $1 \mathrm{~m}^{2}$ circular hardwire mesh cages (height $=30.5 \mathrm{~cm}$ ) were installed and cleared of macroinvertebrates as described above. One freshly deposited communal egg-mass ( $<8 \mathrm{~d}$ old $)$ collected from the neighboring seagrass bed was divided into individual clutches. One clutch was attached with monofilament fishing line to each of 12 pen-shell valves. One valve with capsules, 1 empty valve, and 1 apple murex female was placed in each cage and lids were secured. Cages were checked every 3 to $5 \mathrm{~d}$. Capsule treatments were replaced with fresh clutches $(<8 \mathrm{~d}$ old) every week until the female oviposited. The treatment upon which a female deposited her clutch was scored as her choice.

\section{RESULTS}

\section{Mark-recapture study}

During the 5 mo mark-recapture study, Phyllonotus pomum were most often found partially to almost completely buried either resting, feeding, or mating, but rarely in the same place as previously sighted. Total recovery rate for the experiment was $55.2 \%$ for males and $73 \%$ for females. The average recovery rate per sampling day was 29.1 and $30.4 \%$ for males and females respectively. Males were re-sighted between 0 and 8 times and females were re-sighted between 0 


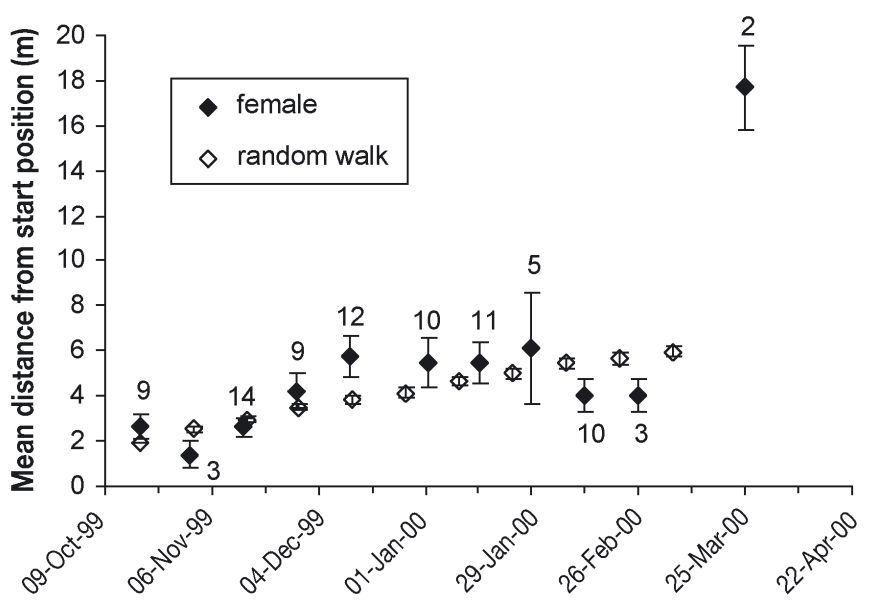

Fig. 2. Phyllonotus pomum. Comparison of movement pattern between females and a random walk model over 5 mo. Bars indicate SE. Numbers indicate sample size of female mean

and 11 times. The 10 females and 13 males never resighted after being labeled or the start position obtained, including 1 of each gender that died (as indicated by empty labeled shells), were not included in the analysis.

The rate of movement was similar over time and between genders. The rate of movement did not significantly change over the 5 mo monitoring period for either gender (females: $\mathrm{r}^{2}=0.05, \mathrm{p}=0.511$; males: $\mathrm{r}^{2}=$ $0.02, p=0.664$ ). Snail size (female: mean $=71.7 \mathrm{~mm}$, $\mathrm{SD}=5.8$, range 56.0 to $84.0 \mathrm{~mm}$; male: mean $=62.2$ $\mathrm{mm}, \mathrm{SD}=3.6$, range 55.5 to $68.5 \mathrm{~mm}$ ) was not significantly correlated with rate of movement (female: $\mathrm{r}^{2}=$ 0.029, $p=0.394$; male: $r^{2}=0.044, p=0.435$ ). Females moved at an average rate of $0.14 \mathrm{~m} \mathrm{~d}^{-1}(\mathrm{SD}=0.08, \mathrm{n}=$ 27 , range 0.02 to $0.33 \mathrm{~m} \mathrm{~d}^{-1}$ ) and males moved at an average rate of $0.19 \mathrm{~m} \mathrm{~d}^{-1}(\mathrm{SD}=0.09, \mathrm{n}=16$, range 0.07 to $0.38 \mathrm{~m} \mathrm{~d}^{-1}$ ). Between genders, there was no significant difference in the mean rate of movement ( $t$-test for equal variance, $t_{0.05[41]}=-1.78, \mathrm{p}=0.083$ ).

In 2 wk, female and male Phyllonotus pomum moved an average of 1.90 and $2.62 \mathrm{~m}$, respectively. These estimates are conservative because the calculations are based on only those individuals that were visible within the observational area on a given date, and used only the linear distance between sighted locations instead of the complete path traveled. The method could not distinguish between buried individuals on the experimental plot or those that moved beyond the observation area. In addition, when the opportunity arose, one female was recorded traveling on the surface at an average rate of $4.63 \mathrm{~cm} \mathrm{~min}^{-1}$ $(\mathrm{SD}=1.24, \mathrm{n}=2)$. This rate is equivalent to $2.78 \mathrm{~m} \mathrm{~h}^{-1}$. Although it is unknown how long a female could sustain this speed, if this rate approximates that of all female apple murex, females should be able to move much farther than the $0.14 \mathrm{~m} \mathrm{~d}^{-1}$ obtained from this study. These rate estimates suggest that oviposition substrates within a $4 \mathrm{~m}$ radius of a communal egg-mass should have been readily accessible to females.

For both females and males, the mean distance moved from the start position was not significantly different from that of a random walk (KolmogorovSmirnov, female: $D=0.273, \mathrm{p}=0.808$; male: $D=0.455$, $\mathrm{p}=0.206$ ) (Fig. 2: females only).

\section{Substrate use and availability}

Communal egg-masses were most frequently deposited on dead pen shells Atrina sp. (70\%, n =60, and $93 \%, \mathrm{n}=43$, in 2000 and 2001, respectively) and occasionally deposited on live pen shells Atrina sp., empty cockle Dinocardium robustum, tulip Fasciolaria tulipa, whelk Busycon contrarium, and clam Chione cancellata shells, or empty mussel shells (Fig. 3). Because substrates other than dead pen shells were used infrequently in comparison, these substrates were pooled for the tests of independence. Whether or not an eggmass was deposited on a dead pen shell was independent of the degree of egg-mass completion ( $G=0.032$, $\mathrm{p}=0.857)$ and of site $(G=1.996, \mathrm{p}=0.158)$. A significantly greater proportion of egg-masses were deposited on dead pen shells in 2001 than in 2000 ( $G=$ 9.177, $p=0.003$ ), a difference that might reflect slight changes in sampling method but which is largely unimportant to the general finding of a propensity to deposit communal egg-masses on dead pen shells.

Pen shells used as oviposition substrate were either whole or fragmented valves. Whole valves had an

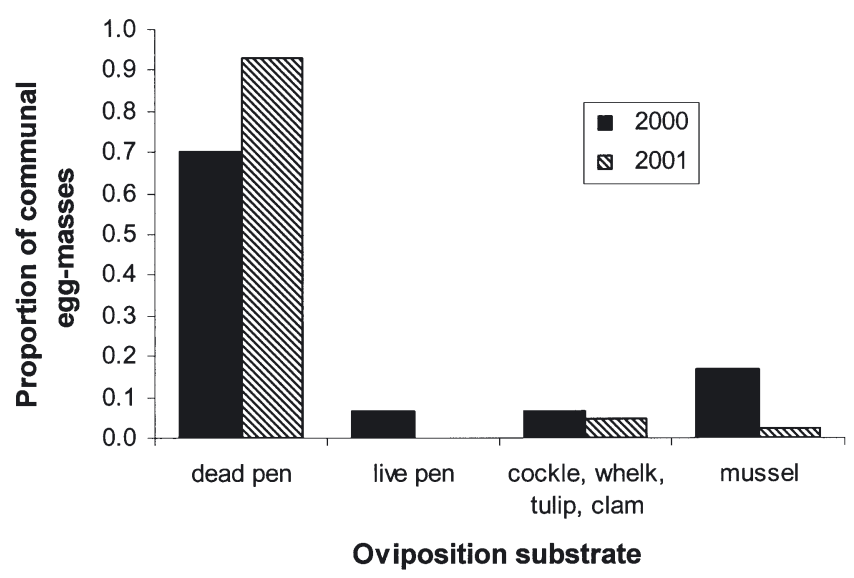

Fig. 3. Phyllonotus pomum. Substrate used for oviposition for 60 communal egg masses in 2000 and 43 communal eggmasses in 2001 


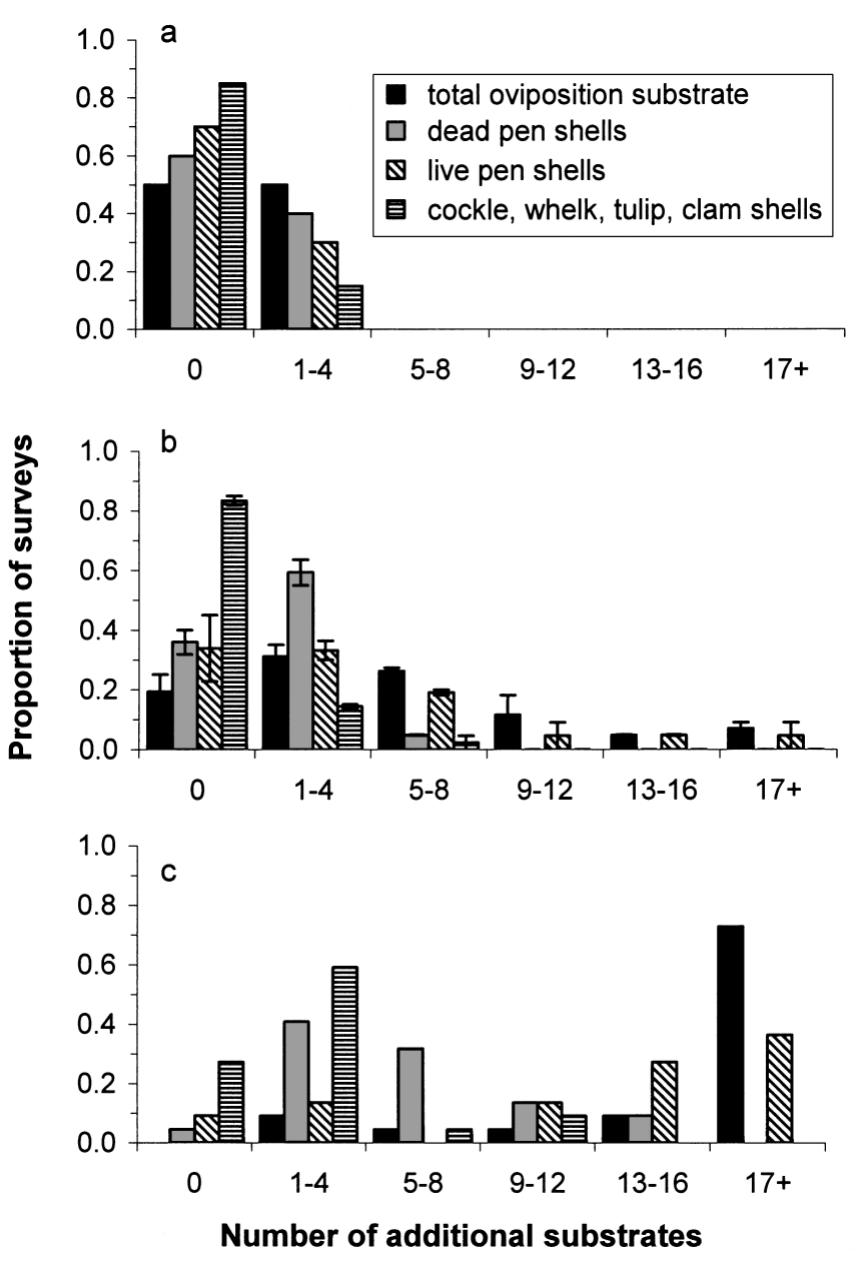

Fig. 4. Phyllonotus pomum. Number of additional oviposition substrates available within (a) 1, (b) 2, and (c) $4 \mathrm{~m}$ of communal egg-masses in the process of being laid. The 'total oviposition substrate' category combines all other categories shown. Data presented for $2 \mathrm{~m}$ surveys are means of 2000 and 2001 with SE bars

average area of $146.0 \mathrm{~cm}^{2}(\mathrm{SD}=77.3, \mathrm{n}=17)$ in 2000 and $169.5 \mathrm{~cm}^{2}(\mathrm{SD}=59.2, \mathrm{n}=14)$ in 2001. Valve fragments had an average area of $129.0 \mathrm{~cm}^{2}(\mathrm{SD}=36.7, \mathrm{n}=$ 9) in 2000 and $125.3 \mathrm{~cm}^{2}(\mathrm{SD}=52.3, \mathrm{n}=14)$ in 2001. The data were pooled because there was no significant difference in substrate area for either substrate type or year (type: $F_{1,53}=3.14, \mathrm{p}=0.082$, year: $F_{1,53}=0.19, \mathrm{p}=$ $0.663)$. There was no significant relationship between substrate area and egg-mass volume $\left(r^{2}=0.006, p=\right.$ 0.587, $\mathrm{n}=54$ ).

In both years, oviposition substrates other than the one occupied by a communal egg-mass were available around communal egg-masses in the process of being deposited. Because of substrate size and time constraints on sampling, mussel shells were not counted individually in these surveys and therefore are excluded from this summary. Both the proportion of surveys containing additional substrates and the number of substrates available increased with increasing distance from a communal oviposition event (Fig. 4). Within a $4 \mathrm{~m}$ radius of a communal oviposition event, every survey contained at least one type of additional oviposition substrate (Fig. 4). Focusing on the most frequently used substrate, the proportion of surveys that contained dead pen shells increased from $40 \%$, to $64 \%$, to $95.5 \%$ for 1,2 and 4 m surveys, respectively. Of these surveys, the number of additional dead pen shells available increased from $1-4$ to $1-8$ to $1-14$ as survey distances increased $(1,2$, and $4 \mathrm{~m}$, respectively). Despite substrate availability near communal oviposition events, females still deposited clutches communally.

Patterns of substrate use did not reflect the proportion of substrate available near communal oviposition events. The proportion of mussel shells was only recorded and included for Year 2000 data. Dead pen shells were used most frequently as oviposition substrate, yet made up only 10 to $20 \%$ of the total substrates surrounding communal oviposition events (Fig. 5). In contrast, live pen shells and empty cockle, tulip, whelk, clam, and mussel shells were used less frequently than available. This result suggests that Phyllonotus pomum prefer and actively seek dead pen shells for oviposition.

\section{Substrate manipulation experiment}

Twenty-two of the 24 cages were used in this analysis. One cage holding a single pen-shell valve was uprooted by a mating pair of horseshoe crabs and the snails escaped. In the second cage, with multiple pen-

Table 1. Phyllonotus pomum. Index of dispersion and the distribution of clutches in each multiple shell-treatment cage for the substrate limitation experiment. Significance values are based on chi-square distribution. ${ }^{*} p<0.05 ;{ }^{* *} p<0.025$;

$$
{ }^{* * *} \mathrm{p}<0.0001
$$

\begin{tabular}{|lcccc|}
\hline $\begin{array}{l}\text { Cage } \\
\text { no. }\end{array}$ & $\begin{array}{c}\mathrm{df} \\
(\mathrm{n}-1)\end{array}$ & $\begin{array}{c}\text { Index of } \\
\text { dispersion }\end{array}$ & $\begin{array}{c}\text { Clutches aggregated? } \\
\text { (Index }>1)\end{array}$ & p-value \\
\hline 2 & 10 & 4.0 & Yes & ${ }^{* * *}$ \\
3 & 9 & 3.0 & Yes & ${ }^{* *}$ \\
4 & 8 & 6.2 & Yes & ${ }^{* * *}$ \\
7 & 8 & 5.0 & Yes & ${ }^{* * *}$ \\
10 & 10 & 6.6 & Yes & ${ }^{* *}$ \\
11 & 8 & 2.0 & Yes & ${ }^{* *}$ \\
12 & 11 & 2.0 & Yes & ${ }^{* * *}$ \\
14 & 11 & 7.4 & Yes & ${ }^{* * *}$ \\
15 & 13 & 4.0 & Yes & ${ }^{* * *}$ \\
17 & 10 & 4.2 & Yes & \\
23 & 10 & 6.2 & Yes & \\
& & & & \\
\hline
\end{tabular}




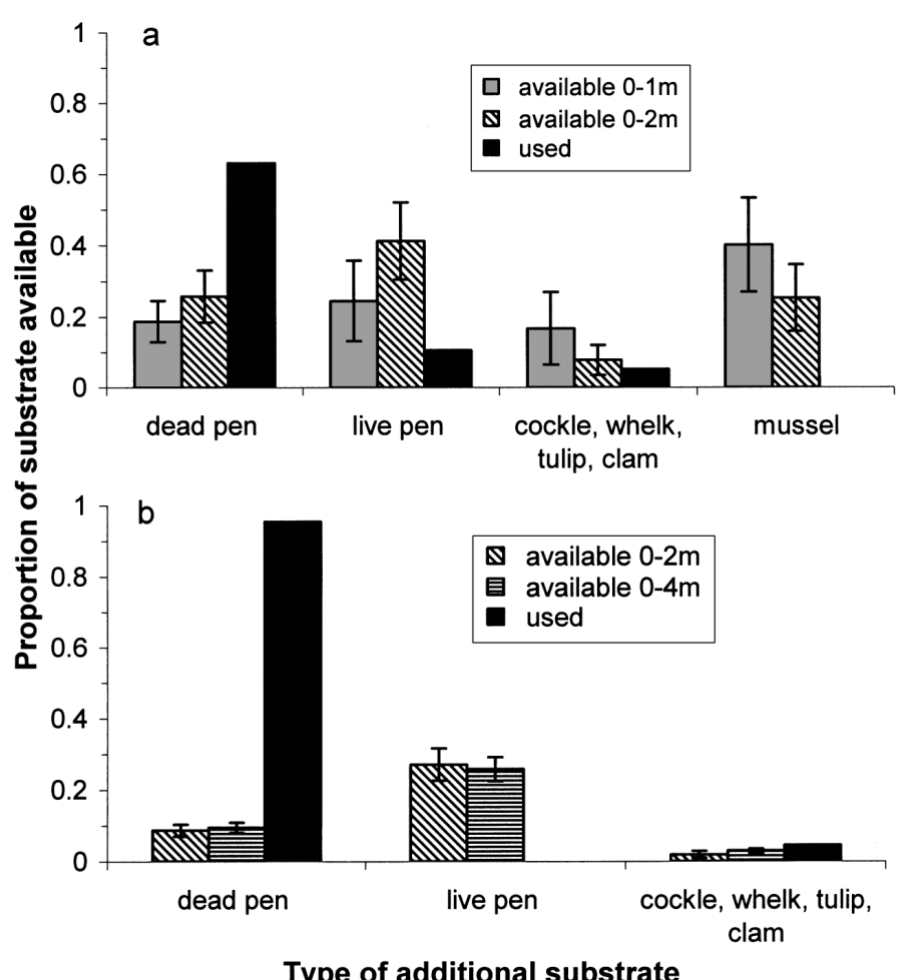

Fig. 5. Phyllonotus pomum. Comparison between the proportion of oviposition substrate used for communal egg-masses in the process of being laid and the mean proportion of additional substrate available within 1, 2, or $4 \mathrm{~m}$ for (a) 2000 and (b) 2001. Mussels were not included as a substrate in 2001 surveys. Bars indicate SE

shell valves, only one female deposited a clutch so this cage could not be used to assess communal behavior. During the experiment, not all females were observed to contribute to egg-masses and a few females were lost, presumably escaping over the curved top of the cage (as indicated by a depression and trail in the sand leading away from the cage). During the experiment, shifting sand covered some pen shells; however, at least 9 shells were always exposed.

Individual clutches were not randomly distributed among shells. In every multiple-shell cage, the index of dispersion was significantly greater than 1 (Table 1), meaning that clutches of egg capsules are aggregated. Therefore, I reject the null hypothesis that females lay randomly with respect to other females. Females choose to deposit clutches with conspecifics.

In both treatments, oviposition behavior resulted in a communal egg-mass. All 11 single-shell treatment cages contained a communal egg-mass deposited on the one pen-shell valve (Fig. 6). In 7 of the 11 multipleshell treatment cages, all clutches were deposited as a communal egg-mass on 1 shell. In the remaining 4 multiple-shell treatment cages, 1 or 2 shells contained individual clutches along with a single shell containing a multi-clutch communal egg-mass. Those females that deposited individual clutches also contributed another clutch to the communal egg-mass.

Oviposition produced similar-sized communal eggmasses even when up to 15 other substrates were available (Fig. 7). There was no significant difference in mean communal egg-mass size between treatments (single-shell: mean $=80.0 \mathrm{ml}, \mathrm{SD}=26.8, \mathrm{n}=11$; multiple-shell: mean $=66.4 \mathrm{ml}, \mathrm{SD}=32.0, \mathrm{n}=11 ; t$-test equal variance, $t_{0.05[20]}=-1.083, p=0.292$ ). In cages containing clutches on more than one shell, individual clutches were significantly smaller than the communal egg-masses (individual: mean $=25.0 \mathrm{ml}, \mathrm{SD}=19.1, \mathrm{n}=$ 4 ; communal: $66.4 \mathrm{ml}, \mathrm{SD}=32.0, \mathrm{n}=11$; $t$-test equal variance, $t_{0.05[13]}=-2.397, \mathrm{p}=0.032$ ).

\section{Choice experiment}

All 10 females that deposited clutches chose one of the 2 pen-shell treatments available; there were no clutches deposited on cage walls. Five females chose shells with previously laid egg capsules and 5 females chose the empty shell. These results suggest that conspecific egg capsules are not responsible for cueing communal oviposition.

Only 2 females that chose the egg capsule treatment stacked their clutch on top of the egg capsules present. The other 8 females deposited their clutch on an empty surface (top or underside of a shell). The placement of capsules in this experiment agrees with field observations of oviposition behavior. With one exception in 2000 and 2001, communal egg-masses were never observed to contain combinations of new, freshly laid clutches deposited on clutches from a previous communal event after a period of time during which no egg-laying has occurred. It was possible to determine the approximate clutch age because freshly laid clutches contain bright, pale yellow capsules with no indication of fouling organisms compared to the duller, slightly darker color and often fouled capsules that have been sitting in the water a while.

\section{DISCUSSION}

This study demonstrated that apple murex snails Phyllonotus pomum did not oviposit communally because of substrate limitation. In the mark-recapture study, females traveled beyond the scale at which substrate would be limiting during egg-laying season. Females did not travel any faster, farther, or use different patterns of movement from males as egg-laying season approached. This is the opposite of what one 


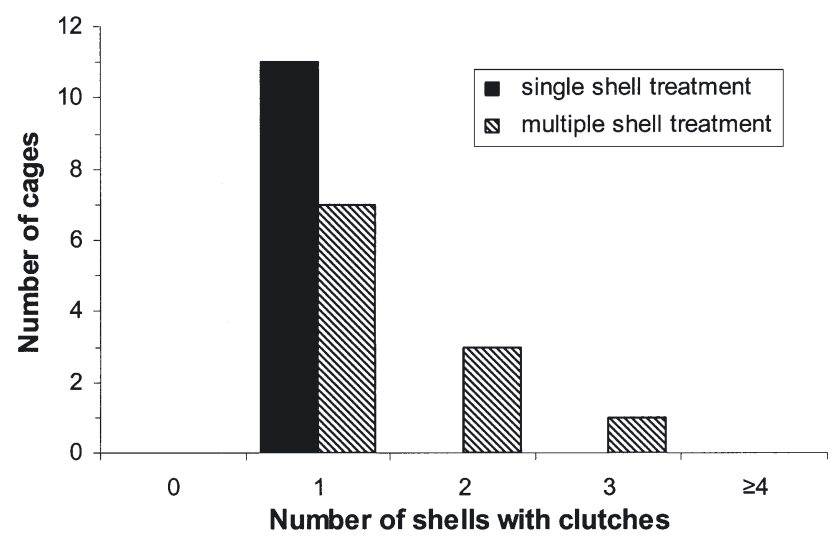

Fig. 6. Phyllonotus pomum. Number of shells on which females deposited clutches for single and multiple shell treatment cages

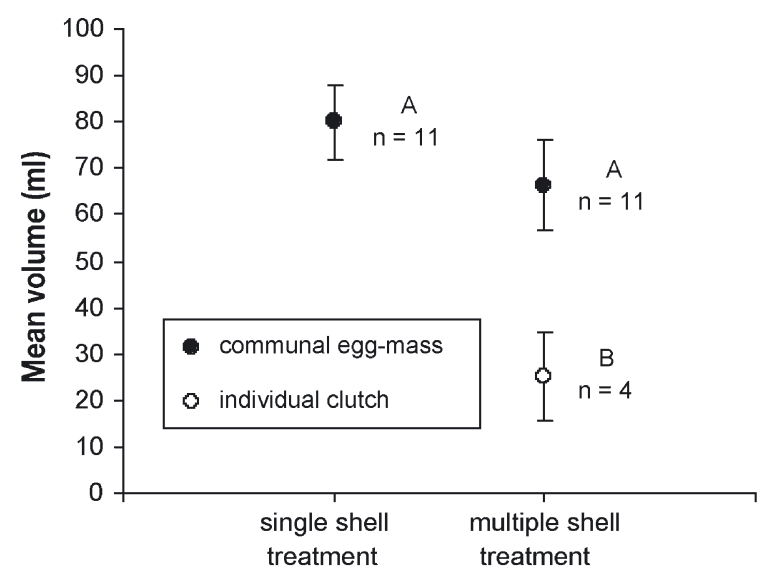

Fig. 7. Phyllonotus pomum. Mean volume of communal eggmasses and individual clutches produced in the single and multiple shell treatment cages. Bars indicate SE. Means with the same letter are not significantly different

might expect if females were actively searching for oviposition substrate. Field surveys indicated that additional shell substrates were present around communal oviposition events; however, the abundance of shells had no effect on communal oviposition behavior. In the field surveys, communal oviposition occurred regardless of whether there were 1 or 14 additional dead pen shells available near a communal oviposition event. In the cage experiment, females chose to aggregate clutches on a single shell even when additional pen shells were available within $0.25 \mathrm{~m}$ of one another. Although this study cannot rule out the possibility that communal egg-laying occurs because most females are attracted to certain characteristics of the chosen substrate, it is unlikely. In every experiment, females always found an appropriate shell and always ovi- posited communally. Additionally, a simple attraction to a particular substrate would not necessarily account for the intense synchrony of egg-laying. This study demonstrated that communal oviposition did not result from a limited number of substrates, which suggests there may be an adaptive advantage to producing communal egg-masses.

Phyllonotus pomum communal egg-masses were found most frequently attached to dead pen shells, which is consistent with substrate dependent oviposition preference demonstrated in gastropods (Barnett et al. 1980). The apparent preference for dead pen shells may be caused by some innate characteristic such as a biofilm particular to this shell (Meadows \& Campbell 1972). Dead pen shells may be preferred over live pen shells because they are not buried in the sand and lack animal tissue, which provides more shell surface area. Although pen shells had a larger surface area than all other oviposition substrates observed in this study, except the one Busycon contrarium (whelk) shell, there was no relationship between pen-shell area and eggmass volume. For the apple murex, a substrate's surface area only affects the first few ovipositing females because most clutches are stacked on top of other females' clutches. The resulting communal egg-mass eventually dwarfs the size of the shell. Therefore, substrate size imposes few restrictions on communal oviposition.

In addition to communal oviposition behavior not being affected by substrate availability, it did not seem to be affected by the presence of conspecific egg capsules. For Phyllonotus pomum, new, freshly laid clutches were rarely found in the field on clutches deposited during a previous communal event after which a period of no egg-laying occurred. In the choice experiment, only 2 of 10 females deposited a clutch on top of previously laid conspecific egg capsules. Alternatively, the act of oviposition may cue aggregation in neighboring $P$. pomum because the formation of proteinaceous capsules may release chemical cues into the water column (D'Asaro 1970, Moore \& Sander 1977). In 2002, one female was observed to travel $2.5 \mathrm{~m}$ in $28 \mathrm{~min}$ at a constant speed directly toward a communal egg-mass in the process of being laid by multiple females. One ovipositing female could signal the presence of suitable substrate, thereby attracting neighboring conspecifcs. This response might lead to communal oviposition independent of substrate abundance. The conspecific 'guide effect' has been demonstrated for shelterseeking juvenile spiny lobsters (Childress \& Herrnkind 1997, 2001), but this hypothesis remains to be tested in gastropods.

The apparent 'choice' of apple murex to oviposit communally regardless of substrate availability and 
abundance suggests that this may be an adaptive behavior. First, communal oviposition may reduce the energetic costs or risks associated with locating dynamic and unpredictable shell resources or competition with fish, crabs, octopi and other gastropods that use empty mollusc shells for reproduction (Kuhlmann 1994). By sharing a resource with conspecifics, females do not risk leaving an oviposition site only to find a lower quality site or no site at all.

Second, communal oviposition could be favored because the 'sheer bulk of a communal egg-mass' may provide protection for developing embryos (D'Asaro 1970, p. 435). For species like Phyllonotus pomum that deposit clutches in stacked communal egg-masses, this adaptive hypothesis includes protection of inner clutches by outer clutches from harmful edge effects such as predation, fouling, or UV light. Aggregating clutches into large communal eggmasses, although more visible in the environment, may dilute predation and create a physical barrier to inner egg capsules. D'Asaro (1970, p. 435) observed 'evidence of extensive predation on the outer layers' only. In a laboratory predation experiment, 4 invertebrates observed to be associated with $P$. pomum communal egg-masses in the field were given 8 to 10 freshly deposited egg-capsules (Swanson 2002). The results showed that the sea urchin Lytechinus variegatus and the xanthid crab Eurypanopeus depressus opened or consumed capsules whereas the proportion of opened capsules in the brittle star Ophioderma sp. and hermit crab Pagurus mclaughlinae treatments did not differ from controls. When pieces of the capsule wall remained in the xanthid crab treatment, most often holes were poked in either side of the capsule base (from each claw) whereas in the sea urchin treatment, jagged-edged halves of capsule walls remained as evidence of being bitten and torn by the Aristotle's lantern (jaw). In this study, capsules with similar damage were observed on the surface of communal egg-masses in the field.

In the field, Phyllonotus pomum communal eggmass surfaces became fouled with time. Fouling microorganisms on the surfaces of gelatinous eggmasses alter oxygen supply (Cohen \& Strathmann 1996) and on proteinaceous capsule walls decrease intracapsular oxygen tension (Cancino et al. 2000). Solar radiation increases embryo mortality within gelatinous egg-masses and proteinaceous egg capsules (Biermann et al. 1992, Rawlings 1996). The size and globular shape of communal egg-masses may serve one, or several, protective functions for inner capsules.

There are potential costs associated with increasing egg-mass size. First, larger egg-masses are more visible and could attract predators. Second, oxygen requirements of developing embryos may impose constraints on egg-mass size and structure (Strathmann \& Strathmann 1995, Lee \& Strathmann 1998). Low levels of oxygen in egg-mass centers can slow or suspend embryo development, decrease shell calcification or delay hatching (Chaffee \& Strathmann 1984, Strathmann \& Strathmann 1995). Therefore, Phyllonotus pomum faces a potential tradeoff that may limit the size of communal egg-masses.

Any cost of aggregation associated with intraspecific competition among hatchlings may be negligible. Competition for food and its effect on juvenile size at hatching occurs among siblings within an egg capsule rather than between juveniles of different parents contributing clutches to communal egg-masses. In addition, the ability of even direct developing offspring to disperse from aggregations, either by crawling, ballooning on mucous threads (Martel \& Chia 1991, González \& Gallardo 1999), or being swept away by water currents, may reduce intraspecific competition after hatching.

One benefit Phyllonotus pomum is unlikely to gain from communal aggregations is increased mating opportunities as has been reported in other marine gastropods (Strathmann 1987). Although there is one report of $P$. pomum males being attracted to communal aggregations (D'Asaro 1970), only ovipositing females were observed on communal egg-masses in this study. There may be little to no opportunity for males to gain paternity during the egg-laying season if females deposit a single clutch or do not leave an egg-mass between clutches. An alternative reproductive strategy for the apple murex may be sperm storage since during the mark and recapture study, mating was observed to occur throughout the year.

This study demonstrated that substrate limitation was not responsible for communal oviposition in Phyllonotus pomum, suggesting there may be advantages to this type of egg-laying behavior. Identifying the factors influencing adult oviposition decisions is important because of the consequences on fitness, especially in non-parental care organisms. It is curious why $P$. pomum oviposit communally and, more importantly, why communal oviposition is a common behavior in gastropods. One must wonder what the costs and benefits are for this behavior. Is it truly a form of protecting egg capsules and the enclosed developing embryos as has been suggested (D'Asaro 1970, 1991, 2000) and if so, what factors pose the greatest threat? Does communal oviposition affect hatching synchrony? What effect does synchrony have on hatchling survival? Pursuing these types of questions may help us gain a better understanding of how communal oviposition is established and maintained. 
Acknowledgements. I would like to thank the Florida State University Marine Lab, St. Joseph's Bay State Park, and the Academic Diving Program for facilitating this work. Various parts of this project were made feasible with the field assistance of B. Shoplock, D. Ferrell, Z. Gokay, K. McGhee, P. Munguia, A. Parsons, D. Swanson, and M. Wise. I appreciate the helpful comments provided by D. Levitan, K. McGhee, P. Munguia, T. McGovern, W. Herrnkind, R. Ellington, S. Levings and anonymous reviewers. This study received financial support from the Society of Integrative and Comparative Biology's Grant-in-Aid-of Research.

\section{LITERATURE CITED}

Barnett PRO, Hardy BLS, Watson J (1980) Substratum selection and egg-capsule deposition in Nassarius reticulatus (L.). J Exp Mar Biol Ecol 45:95-103

Biermann CH, Schinner GO, Strathmann RR (1992) Influence of solar radiation, microalgal fouling, and current on deposition site and survival of embryos of a dorid nudibranch gastropod. Mar Ecol Prog Ser 86:205-215

Brenchley GA (1981) Limiting resources and the limits to reproduction in the mud snails Ilyanassa obsoleta in Barnstable Harbor, Massachusetts. Biol Bull 161:323

Cancino JM, Gallardo JA, Torres F, Leiva G, Navarro JM (2000) Effects of sessile Protozoa on intracapsular oxygen tension and embryonic shell calcification in the muricid Chorus giganteus. Mar Ecol Prog Ser 200:141-148

Chaffee C, Strathmann RR (1984) Constraints on egg masses. I. Retarded development within thick egg masses. J Exp Mar Biol Ecol 84:73-83

Childress MJ, Herrnkind WF (1997) Den sharing by juvenile Caribbean spiny lobsters (Panulirus argus) in nursery habitat: cooperation or coincidence? Mar Freshw Res 48: 751-758

Childress MJ, Herrnkind WF (2001) The guide effect influence on the gregariousness of juvenile Caribbean spiny lobsters. Anim Behav 62:465-472

Cohen CS, Strathmann RR (1996) Embryos at the edge of tolerance: effects of environment and structure of egg masses on supply of oxygen to embryos. Biol Bull 190:8-15

Danchin E, Wagner RH (1997) The evolution of coloniality: the emergence of new perspectives. Trends Ecol Evol 12: 342-347

D'Asaro CN (1970) Egg capsules of Prosobranch mollusks from south Florida and the Bahamas, and notes on spawning in the laboratory. Bull Mar Sci 20:414-440

D'Asaro CN (1986) Egg capsules of eleven marine prosobranchs from northwest Florida. Bull Mar Sci 39:76-91

D'Asaro CN (1991) Gunnar Thorson's world-wide collection of Prosobranch egg capsules: Muricidae. Ophelia 35: $1-101$

D'Asaro CN (1993) Gunnar Thorson's world-wide collection of Prosobranch egg capsules: Nassaridae. Ophelia 38: $149-215$

D'Asaro CN (2000) Gunnar Thorson's world-wide collection of Prosobranch egg capsules: Fasciolaridae. Ophelia 52:

Editorial responsibility: Otto Kinne (Editor),

Oldendorf/Luhe, Germany
$77-112$

DeMartini EE (1991) Spawning success of the male plainfin midshipman. II. Substratum as a limiting spatial resource. J Exp Mar Biol Ecol 146:235-251

Fan XM, Wu B, Nagle GT, Painter SD (1997) Molecular cloning of a cDNA encoding a potential water-borne pheromonal attractant released during Aplysia egg laying. Mol Brain Res 48:167-170

González KA, Gallardo CS (1999) Embryonic and larval development of the muricid snail Chorus giganteus (Lesson, 1829) with an assessment of the developmental nutrition source. Ophelia 51:77-92

Krebs CJ (1999) Ecological methodology, 2nd edn. Benjamin/ Cummings, Mento Park, CA

Kuhlmann ML (1994) Indirect effects of a predatory gastropod in a seagrass community. J Exp Mar Biol Ecol 183:163-178

Kuhlmann ML (1997) Regulation of fish reproduction by a predatory gastropod: an experimental investigation of indirect effects in a seagrass community. J Exp Mar Biol Ecol 218:199-214

Kuhlmann ML (1998) Spatial and temporal patterns in the dynamics and use of pen shells (Atrina rigida) as shelters in St. Joseph Bay, Florida. Bull Mar Sci 218:199-214

Lee CE, Strathmann RR (1998) Scaling of gelatinous clutches: effects of siblings' competition for oxygen on clutch size and parental investment per offspring. Am Nat 151:293-310

Martel A, Chia FS (1991) Drifting and dispersal of small bivalves and gastropods with direct development. J Exp Mar Biol Ecol 150:131-147

Meadows PS, Campbell JI (1972) Habitat selection by aquatic invertebrates. In: Russell FS, Yonge M (eds) Advances in marine biology, Vol 10. Academic Press, New York, p 271-382

Moore EA, Sander F (1977) Spawning and early life history of Murex pomum Gmelin, 1791. Veliger 20:251-259

Pechenik JA (1978) Adaptations to intertidal development: studies on Nassarius obsoletus. Biol Bull 154:282-291

Ramsay SM, Otter K, Ratcliffe LM (1999) Nest-site selection by female Black-capped Chickadees: settlement based on conspecific attraction? Auk 116:604-617

Rawlings TA (1996) Shields against ultraviolet radiation: an additional protective role for the egg capsules of benthic marine gastropods. Mar Ecol Prog Ser 136:81-95

Sokal RR, Rohlf FJ (1995) Biometry, 3rd edn. WH Freeman, New York

Strathmann MF (1987) Reproduction and development of marine invertebrate of the Northern Pacific Coast. University of Washington Press, Seattle

Strathmann RR, Strathmann MF (1995) Oxygen supply and limits on aggregation of embryos. J Mar Biol Assoc UK 75: 413-428

Swanson CA (2002) Communal oviposition in the apple murex snail Phyllonotus pomum: the effect of substrate availability and the tradeoffs associated with increasing egg mass volume. MSc thesis, Florida State University, Tallahassee

Zar JH (1999) Biostatistical analysis, 4th edn. Prentice Hall, Upper Saddle River, NJ

Submitted: October 9, 2003; Accepted: March 9, 2004

Proofs received from author(s): June 2, 2004 